\title{
Polyethylene Glycol Mediated Kinetic Study of Nitro Decarboxylation of $\alpha, \beta$-Unsaturated Acids by Blau's Fe(III) Phen Complex
}

\author{
K. Ramesh, ${ }^{1}$ S. Shylaja, ${ }^{1}$ K. C. Rajanna, ${ }^{2}$ P. Giridhar Reddy, ${ }^{1}$ and P. K. Saiprakash ${ }^{2}$ \\ ${ }^{1}$ Department of Chemistry, CBIT, Gandipet, Hyderabad 500 075, India \\ ${ }^{2}$ Department of Chemistry, Osmania University, Hyderabad 500 007, India
}

Correspondence should be addressed to K. C. Rajanna; kcrajannaou@yahoo.com

Received 17 May 2013; Accepted 11 August 2013

Academic Editor: Charles A. Mebi

Copyright (C) $2013 \mathrm{~K}$. Ramesh et al. This is an open access article distributed under the Creative Commons Attribution License, which permits unrestricted use, distribution, and reproduction in any medium, provided the original work is properly cited.

Polyethylene glycol (PEG) mediated kinetic study of nitro decarboxylation of $\alpha, \beta$-unsaturated acids (USA) has been taken up by Blau's [Fe(III) nitrate-Phen] yellow complex in acetonitrile medium. Kinetics of the reactions indicated Michaelis-Menton type of mechanism and rate law. Reaction rates are significantly influenced by the structural variation and concentration of PEG. Catalysis of PEG was explained on the lines of nonionic micelles such as TX-100 because of their structural resemblance and also due to a slight negative charge developed on polyoxyethylene and cationic form(s) of $\mathrm{Fe}(\mathrm{III})$ chelates in the intermediate stages.

\section{Introduction}

The concept of atom efficiency has proven to be a popular tool in the evaluation of the "greenness" of a chemical process [1], which revealed a comparison between various sectors of chemical manufacturing. In pharmaceutical and fine chemicals manufacturing, the high value of the product has been particularly a significant feature in the establishment of many highly (atom) inefficient processes. Thus, the creation and use of green chemical conditions are more important in pharmaceutical and fine chemicals manufacturing. In the direction of achieving green chemical processes, catalysis not only helps in replacing reagents or enabling more efficient processes, but the demonstration of their value in reducing the environmental hazardness impact and the costs of the processes. The cost reduction of the processes will also catalyze the greening of chemistry $[2,3]$. In view of the above striking features, there has been an upsurging interest in the search of eco-friendly catalysts, which satisfy the conditions of green chemistry or at least improve the greenery of reaction conditions. The most significant alternatives include (a) the use of eco-friendly materials as catalysts, (b) environmentally benign solvents such as water and polyethylene glycols (PEGs) [4-6], (c) the use of nonconventional energy sources such as sonication (by using ultrasonic waves) and microwave (MW) irradiation [7]. A special attention has also been focused on conducting the reactions under solvent free conditions by grinding the reactants in a mortar with a pestle or by microwave irradiation to achieve greenery conditions [8]. For the past few decades our group has also been actively engaged in exploiting the use of the above cited tools to assist various organic transformations such as Vilsmeier-Haack, Hunsdiecker [9-11], and nitration reactions [12-14].

It is customary to measure the efficiency of a catalyst by the number of reusable cycles. Similarly, the value of a new solvent medium basically depends on its environmental impact, the ease with which it could be recycled, and solvent properties, namely, low vapor pressure, nonflammability, and high polarity for solubilization. In performing the majority of organic transformations, solvents also play an important role in mixing the ingredients to make the system homogeneous and allow molecular interactions to be more efficient. Polyethylene glycol (PEG) is a neutral, hydrophilic polyether and is less expensive. The use of PEG avoids the use of acid or base catalysts, and moreover PEG can be recovered and reused. Thus, it offers a convenient, inexpensive, nonionic, 
<smiles>CCOCC(C)O</smiles>

(I) Structure of polyethylene glycol (PEG)

Scheme 1

nontoxic, and recyclable reaction medium for the replacement of volatile organic solvents. This protocol also offers a rapid and clean alternative and reduces reaction times; see Scheme 1.

On the other hand, it is unreasonable to note that over the years, transition metal ions or their complexes with different environments have been used as catalysts, probably because they are economically cheap and available in any laboratory desk. Ferric salts or the complexes of Fe(III) have also been in the forefront as efficient catalysts under homogeneous as well as heterogeneous conditions. Earlier reports show that $\mathrm{Fe}(\mathrm{III})$ oxidation reactions are sluggish in acidic media and do not proceed in highly concentrated solutions. However, the addition of even trace amounts of Phenanthroline (Phen) to the reaction medium increases the formal potential of $\mathrm{Fe}(\mathrm{II}) / \mathrm{Fe}$ (III) couple, rendering the reaction thermodynamically feasible by forming yellow colored Fe(III) chelates [1518]. Phenanthroline functions as a typical bidentate chelate molecule which interacts with metal ion through the nitrogen atoms with the formation of five-membered rings. Further, it is interesting to note that the above mentioned yellow complexes of Fe(III) are isolated as crystalline solids and wellcharacterized by Blau [15]. These complexes are reported to be substitution labile and entirely different from ferroin (blue complexes of Fe(III) with Phen), which could not be obtained by direct mixing but only by the oxidation of ferroin and were also found to be substitution inert.

Borodin [19] was the first to report the classical Hunsdiecker-Borodin reaction (HBR) in the year 1861. Hunsdiecker et al. [20, 21] later on developed this reaction in 1942. It is one of the most versatile reactions in organic synthesis for the conversion of $\alpha, \beta$-unsaturated aromatic carboxylic acids to $\beta$-bromostyrenes. The reaction also depicted that silver carboxylates when treated with molecular bromine at reflux temperatures underwent facile bromo decarboxylation to afford the corresponding alkyl bromides. Over a period of years, this reaction underwent several modifications as evidenced from quite a few number of publications [2228 ]. In view of these striking features, the author has taken up nitration of $\alpha, \beta$-unsaturated acids in this chapter using Blau's yellow complexes of Fe(III) (ferric nitrate and Phen) in PEG media by avoiding mineral acids completely. In order to throw light on the most effective PEG, we have used an array of PEGs in this study.

\section{Experimental}

All the $\alpha, \beta$-unsaturated acids used in the present study are AnalaR grade and obtained from BDH, Merck, Aldrich, Fluka, or Loba chemicals. The rest of the chemicals are procured from BDH-Merck, India. Polyethylene glycols (PEGs) were used as such which were procured from the suppliers. HPLC grade Acetonitrile was used throughout the study.

2.1. General Procedure for Solvent Mediated Synthesis of $\beta$ Nitro Styrene. In this procedure, reactions are conducted using DCE and MeCN as solvents. Cinnamic acid (0.001 mol) dissolved in DCE/MeCN and 0.001 moles of Blau's complex (mixture of equimolar mixture of $\mathrm{Fe}$ (III) nitrate and 1,10Phenanthroline (Phen) ligand) were suspended in a three necked round bottomed flask. The flask is equipped with a mechanical stirrer and reflux condenser. The reaction mixture is stirred for some time until the evolution of $\mathrm{CO}_{2}$ completely ceases. The mixture is cooled in an ice bath and the precipitate is removed by filtration. The residue is washed with $\mathrm{CCl}_{4}$ and the filtrates are combined. The solvent is removed by distillation using a modified Claisen distillation apparatus with a $6 \mathrm{~cm}$ condenser. After completion of the reaction as indicated by TLC, the reaction mixture is quenched with $2 \%$ sodium carbonate solution, and the organic layer was separated, dried over $\mathrm{Na}_{2} \mathrm{SO}_{4}$, evaporated under vacuum, and purified with column chromatography using ethylacetate: hexane $(3: 7)$ as eluent to get pure product. Table 1 shows the reaction times, and under kinetic conditions also, the product of the reaction was found to be $\beta$-nitro styrene as characterized by spectroscopic methods (Table 2). But the reactions are too sluggish with long reaction times even at elevated temperatures, and the yields are too low under these conditions.

2.2. Kinetic Measurements. Progress of the reaction was followed by recording the absorbance values of the product of oxidation [Fe(II)-(Phen) complex] produced as a function of time at $510 \mathrm{~nm}$ (molar absorptivity $-\varepsilon=1.11 \times$ $10^{4} \mathrm{dm}^{3} \mathrm{~mol}^{-1} \mathrm{~cm}^{-1}$ ) on a Beckman-DU model spectrophotometer (equipped with thermostatic cell compartments). Control experiments revealed that the products of oxidation, that is, $\mathrm{Fe}$ (II) chelates are quite stable under the experimental conditions.

\section{Results and Discussion}

3.1. Salient Kinetic Features. (1) Under pseudo first order conditions, namely, (i) [Phen] $\gg[\mathrm{Fe}(\mathrm{III})],[\mathrm{USA}] \gg[\mathrm{Fe}(\mathrm{III})]$; in the case of Blau's yellow complexes the plots of $\ln (a /(a-x))$ or $\left[\ln \left(A_{\infty}-A_{0}\right) /\left(A_{\infty}-A_{t}\right)\right]$ versus time were found to be linear with negative gradients in all the systems studied. First order rate constant $\left(k^{\prime}\right)$ could be obtained either by pointwise calculation using first order rate expression or from the slopes of linear plots cited $\left(k^{\prime}\right)$. Both the values agreed with each other. This observation indicates first order with respect to [Fe(III) Phen] in all the systems. Similar observations were noticed when the reactions were studied in all PEG media (Figures 1 and 2).

(2) This reaction is also conducted under second order conditions with equal concentrations of [Phen] $[\mathrm{Fe}(\mathrm{III})]_{\mathrm{o}}=[\mathrm{S}]_{0}$. Kinetic plots of $[1 /(a-x)]$ or $\left[1 /\left(A_{\infty}-\right.\right.$ $\left.A_{t}\right)$ ] versus time have been found linear with a positive gradient and definite intercept on ordinate vertical axis, indicating overall second order kinetics (Figures 3 and 4). 
TABLE 1: Effect of different PEGs on Fe (III)-Phen triggered nitro Hunsdiecker reactions with unsaturated carboxylic acids.

\begin{tabular}{|c|c|c|c|c|c|c|c|c|c|c|c|c|c|}
\hline \multirow{2}{*}{ Entry } & \multirow{2}{*}{ Substrates } & \multicolumn{2}{|c|}{ Without PEG } & \multicolumn{2}{|c|}{ PEG-200 } & \multicolumn{2}{|c|}{ PEG-300 } & \multicolumn{2}{|c|}{ PEG-400 } & \multicolumn{2}{|c|}{ PEG-600 } & \multicolumn{2}{|c|}{ PEG-6000 } \\
\hline & & RT (hr) & Yield (\%) & RT (hr) & Yield (\%) & RT (hr) & Yield (\%) & RT (hr) & Yield (\%) & RT (hr) & Yield (\%) & RT (hr) & Yield (\%) \\
\hline 1 & $\mathrm{CA}$ & 26 & 55 & 2.50 & 78 & 1.75 & 86 & 1.75 & 82 & 1.75 & 80 & 3.0 & 75 \\
\hline 2 & 4-ClCA & 28 & 60 & 3.0 & 75 & 2.00 & 85 & 2.50 & 80 & 2.75 & 80 & 3.75 & 78 \\
\hline 3 & 4-OMeCA & 24 & 70 & 1.75 & 80 & 1.50 & 94 & 1.50 & 84 & 1.75 & 82 & 2.75 & 80 \\
\hline 4 & 4-MeCA & 24 & 60 & 2.0 & 80 & 1.50 & 90 & 1.75 & 84 & 2.0 & 80 & 2.75 & 78 \\
\hline 5 & $4-\mathrm{NO}_{2} \mathrm{CA}$ & 28 & 55 & 3.0 & 70 & 2.00 & 82 & 2.75 & 78 & 3.0 & 75 & 4.0 & 65 \\
\hline 6 & 4-OHCA & 24 & 65 & 2.0 & 78 & 1.50 & 90 & 1.75 & 86 & 1.75 & 82 & 2.75 & 80 \\
\hline 7 & AA & 26 & 63 & 2.0 & 76 & 1.50 & 92 & 1.75 & 88 & 2.0 & 86 & 2.75 & 82 \\
\hline 8 & CRA & 28 & 65 & 3.0 & 75 & 2.00 & 85 & 2.75 & 80 & 3.0 & 78 & 4.0 & 70 \\
\hline 9 & 3-PhCRA & 26 & 70 & 2.75 & 76 & 1.50 & 90 & 1.50 & 85 & 2.0 & 78 & 2.75 & 72 \\
\hline 10 & 2-ClCA & 28 & 60 & 3.0 & 80 & 2.00 & 86 & 2.00 & 82 & 2.75 & 80 & 4.0 & 78 \\
\hline 11 & 2-MeCA & 25 & 55 & 2.0 & 78 & 1.50 & 88 & 1.50 & 82 & 1.75 & 80 & 2.75 & 75 \\
\hline
\end{tabular}

TABLE 2: NMR and mass spectral data for selected reaction products.

\begin{tabular}{|c|c|c|c|c|}
\hline \multirow{2}{*}{ Entry } & \multirow{2}{*}{ Substrates } & \multirow{2}{*}{ Product } & \multicolumn{2}{|c|}{ Spectral data } \\
\hline & & & $m / z$ & ${ }^{1} \mathrm{H}$ NMR \\
\hline 1 & $\mathrm{CA}$ & $\beta$-Nitro styrene & 149 & $\begin{array}{l}\delta 6.4(\mathrm{~d} 1 \mathrm{H}, \beta-\mathrm{CH}) ; \delta 7.3-7.65(\mathrm{~m} \mathrm{5H}, \mathrm{Ar}-\mathrm{H}) \\
\delta 7.8(\mathrm{~d} 1 \mathrm{H}, \alpha-\mathrm{CH})\end{array}$ \\
\hline 2 & 4-ClCA & 4-Chloro $\beta$-nitro styrene & 184 & $\begin{array}{l}\delta 6.6(\mathrm{~d} 1 \mathrm{H}, \beta-\mathrm{CH}) ; \delta 7.2(\mathrm{~d} 2 \mathrm{H}, \mathrm{Ar}-\mathrm{H}) \\
\delta 7.6(\mathrm{~d} 2 \mathrm{H}, \mathrm{Ar}-\mathrm{H}) ; \delta 8.3(\mathrm{~d} 1 \mathrm{H}, \alpha-\mathrm{CH}) \\
\end{array}$ \\
\hline 3 & 4-OmeCA & 4-Methoxy $\beta$-nitro styrene & 179 & $\begin{array}{l}\delta 3.8\left(\mathrm{~s} 3 \mathrm{H}, \mathrm{OCH}_{3}\right) ; \delta 6.4(\mathrm{~d} 1 \mathrm{H}, \beta-\mathrm{CH}) \\
\delta 7.32-7.7(\mathrm{~m} 4 \mathrm{H}, \mathrm{Ar}-\mathrm{H}) \\
\delta 7.9(\mathrm{~d} 1 \mathrm{H}, \alpha-\mathrm{CH})\end{array}$ \\
\hline 4 & 4-MeCA & 4-Methyl $\beta$-nitro styrene & 163 & $\begin{array}{l}\delta 3.0\left(\mathrm{~s} 3 \mathrm{H}, \mathrm{CH}_{3}\right) ; \delta 6.6(\mathrm{~d} \mathrm{1H}, \beta-\mathrm{CH}) \\
\delta \text { 7.4-7.7 (m } 4 \mathrm{H}, \mathrm{Ar}-\mathrm{H}) ; \delta 7.9(\mathrm{~d} 1 \mathrm{H}, \alpha-\mathrm{CH}) \\
\end{array}$ \\
\hline 5 & $4-\mathrm{NO}_{2} \mathrm{CA}$ & 4-Nitro $\beta$-nitro styrene & 194 & $\begin{array}{l}\delta 6.6(\mathrm{~d} 1 \mathrm{H}, \beta-\mathrm{CH}) ; \delta 7.4(\mathrm{~d} 2 \mathrm{H}, \mathrm{Ar}-\mathrm{H}) \\
\delta 7.8(\mathrm{~d} 2 \mathrm{H}, \mathrm{Ar}-\mathrm{H}) ; \delta 8.2(\mathrm{~s} 1 \mathrm{H}, \alpha-\mathrm{CH}) \\
\end{array}$ \\
\hline 6 & 4-OHCA & 4-Hydroxy $\beta$-nitro styrene & 165 & $\begin{array}{l}\delta 6.5(\mathrm{~d} 1 \mathrm{H}, \beta-\mathrm{CH}) ; \delta 7.3(\mathrm{~d} 2 \mathrm{H}, \mathrm{Ar}-\mathrm{H}) \\
\delta 7.8(\mathrm{~d} 2 \mathrm{H}, \mathrm{Ar}-\mathrm{H}) ; \delta 8.1(\mathrm{~d} 1 \mathrm{H}, \alpha-\mathrm{CH}) \\
\delta 10.5(\mathrm{~s} 1 \mathrm{H}, \mathrm{Ar}-\mathrm{OH})\end{array}$ \\
\hline 7 & AA & 1-Nitro ethene & 73 & $\begin{array}{l}\delta 5.92(\mathrm{~d} 1 \mathrm{H}, \beta-\mathrm{CH}) \\
\delta 6.6(\mathrm{~d} 1 \mathrm{H}, \operatorname{trans} \beta-\mathrm{CH}) \\
\delta 7.25(\mathrm{q} 1 \mathrm{H}, \alpha-\mathrm{CH})\end{array}$ \\
\hline 8 & CRA & 1-Nitro propene & 87 & $\begin{array}{l}\delta 2.12\left(\mathrm{~d} 3 \mathrm{H}, \mathrm{CH}_{3}\right) ; \delta 7.0(\mathrm{~d} \mathrm{1H}, \alpha-\mathrm{CH}) \\
\delta 7.15(\mathrm{~m} \mathrm{1H}, \beta-\mathrm{CH})\end{array}$ \\
\hline 9 & 3-PhCRA & 3-Phenyl 1-nitro propene & 163 & $\begin{array}{l}\delta 3.3\left(\mathrm{~d} 2 \mathrm{H}, \mathrm{CH}_{2}\right) ; \delta 7.23-7.33(\mathrm{~m} 5 \mathrm{H}, \mathrm{Ar}-\mathrm{H}) \\
\delta 8.2(\mathrm{~d} 1 \mathrm{H}, \alpha-\mathrm{C}-\mathrm{H})\end{array}$ \\
\hline 10 & 2-ClCA & 2-Chloro $\beta$-nitro styrene & 183 & $\begin{array}{l}\delta 6.6(\mathrm{~d} 1 \mathrm{H}, \beta-\mathrm{CH}) ; \delta 7.3-7.7(\mathrm{~m} 4 \mathrm{H}, \mathrm{Ar}-\mathrm{H}) \\
\delta 8.2(\mathrm{~d} 1 \mathrm{H}, \alpha-\mathrm{C}-\mathrm{H})\end{array}$ \\
\hline 11 & 2-MeCA & 2-Methyl $\beta$-nitro styrene & 163 & $\begin{array}{l}\delta 2.9\left(\mathrm{~s} 3 \mathrm{H}, \mathrm{CH}_{3}\right) ; \delta 6.7(\mathrm{~d} \mathrm{1H}, \beta-\mathrm{CH}) \\
\delta 7.1-7.8(\mathrm{~m} 4 \mathrm{H}, \mathrm{Ar}-\mathrm{H}) ; \delta 8.2(\mathrm{~d} 1 \mathrm{H}, \alpha-\mathrm{CH})\end{array}$ \\
\hline
\end{tabular}

Since the order with respect to $[\mathrm{Fe}(\mathrm{III})]$ is one under pseudo conditions, this observation suggests that order in $[\mathrm{S}]$ is also one. Thus, from the foregoing process of kinetic results, we conclude that [Fe(III) Phen] mediated Hunsdiecker-Borodin reaction follows an overall second order kinetics.

(3) Even though the plots of $1 / k^{\prime}$ versus $1 /[$ Phen] as well as $1 / k^{\prime}$ versus $1 /[\text { Phen }]^{2}$ were found linear with positive slope and intercept on $1 / k^{\prime}$-axis, the plots between $\left(1 / k^{\prime}\right)$ and
$1 /\left[\right.$ Phen] indicated better correlation coefficients $\left(R^{2}>0.990\right)$ than those obtained from $1 / k^{\prime}$ versus $1 /[\text { Phen }]^{2}$ plots. These observations probably suggest the formation of a precursor (formation of 1:1 Fe(III)-Phen complex) between Fe(III) and Phen. Similar observations were recorded in all PEG media and the representative data are presented in Figure 5.

(4) All the reactions have been studied in different PEG media and significant rate enhancements were observed. 


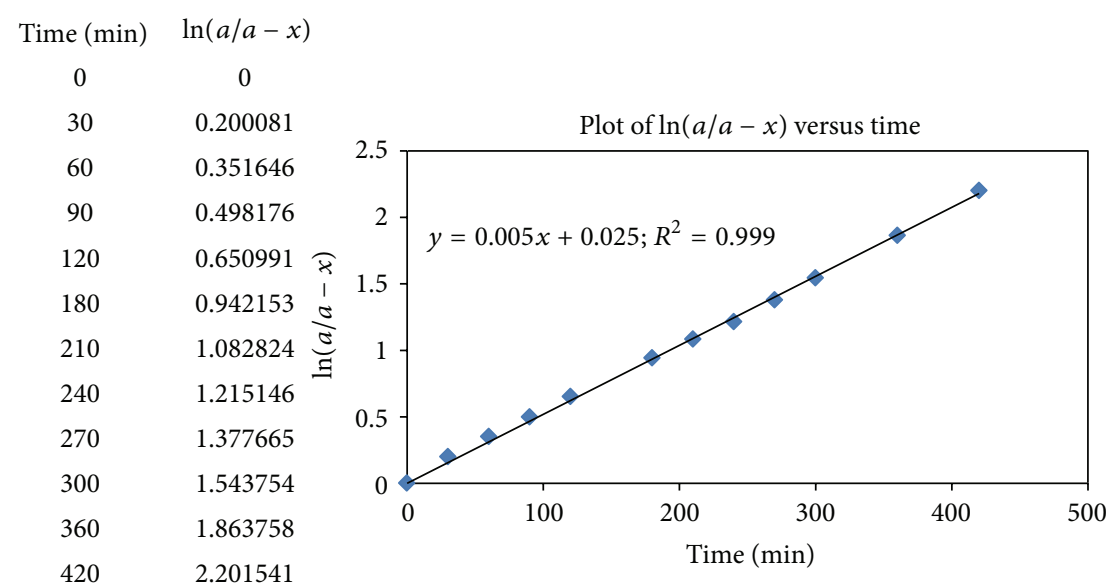

Figure 1: Pseudo first order kinetic plot of cinnamic acid $\left(\ln \left(A_{\infty}-A_{t}\right)\right.$ versus time $)$ at $313 \mathrm{~K}$. $[\mathrm{CA}]=6.25 \times 10^{-3} \mathrm{~mol} \mathrm{dm}^{-3} ;[\mathrm{Phen}]=3.75 \times$ $10^{-3} \mathrm{~mol} \mathrm{dm}^{-3} ;[\mathrm{Fe}(\mathrm{III})]=1.25 \times 10^{-3} \mathrm{~mol} \mathrm{dm}^{-3} ;[\mathrm{PEG}-200]=9.37 \times 10^{-1} \mathrm{~mol} \mathrm{dm}^{-3}$.

$\begin{array}{cc}\text { Time }(\min ) & \ln (a / a-x) \\ 0 & 0 \\ 30 & 0.312812 \\ 60 & 0.553269 \\ 90 & 0.841066 \\ 120 & 1.04277 \\ 150 & 1.289373 \\ 180 & 1.499445 \\ 210 & 1.765713 \\ 240 & 2.014609 \\ 270 & 2.342053 \\ 300 & 2.598728 \\ 360 & 3.078301 \\ 420 & 3.563809\end{array}$

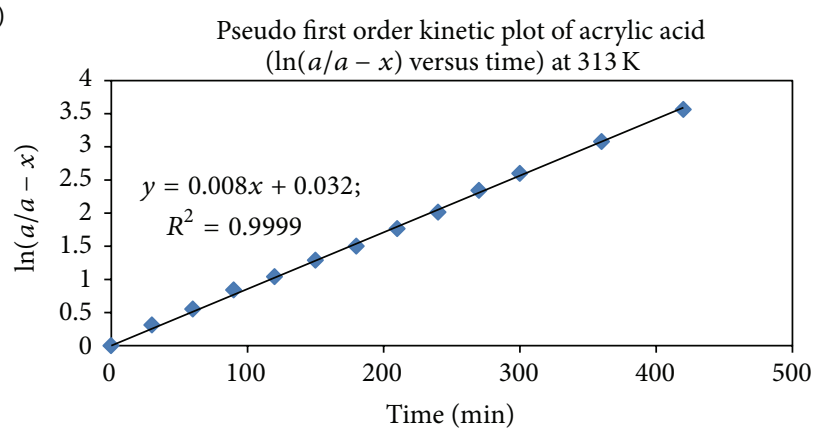

FIGURE 2: Pseudo first order kinetic plot of acrylic acid $\left(\ln \left(A_{\infty}-A_{t}\right)\right.$ versus time $)$ at $313 \mathrm{~K}$. $[\mathrm{AA}]=6.25 \times 10^{-3} \mathrm{~mol} \mathrm{dm}^{-3}$; $[\mathrm{Phen}]=3.75 \times$ $10^{-3} \mathrm{~mol} \mathrm{dm}^{-3} ;[\mathrm{Fe}(\mathrm{III})]=1.25 \times 10^{-3} \mathrm{~mol} \mathrm{dm}^{-3} ;\left[\right.$ PEG-300] $=6.24 \times 10^{-1} \mathrm{~mol} \mathrm{dm}^{-3}$.

3.2. Reactive Species. Although reactive Fe(III) species are complicated, Whiteker and Davidson [17] were the first to give a clear picture regarding the formation and analysis of various types of $\mathrm{Fe}(\mathrm{III})$ species in aqueous sulphuric acid medium. On similar lines various forms of $\mathrm{Fe}$ (III) nitrate species such as $\mathrm{Fe}\left(\mathrm{NO}_{3}\right)_{3}, \mathrm{Fe}^{+}\left(\mathrm{NO}_{3}\right)_{2}, \mathrm{Fe}^{2+}\left(\mathrm{NO}_{3}\right), \mathrm{Fe}^{3+}(\mathrm{aq})$, and $\mathrm{Fe}(\mathrm{OH})^{2+}$ could be formulated. $\mathrm{Fe}^{3+}(\mathrm{aq})$ forms $\mathrm{Fe}(\mathrm{OH})^{2+}$ upon hydrolysis,

$$
\mathrm{Fe}^{3+}+\mathrm{H}_{2} \mathrm{O} \stackrel{K_{h}}{\leftrightarrows} \mathrm{Fe}(\mathrm{OH})^{2+}+\mathrm{H}^{+}
$$

$K_{h}$ value for this reaction was reported as $2.0 \times 10^{-3}$ at $27^{\circ} \mathrm{C}$. $\mathrm{Fe}^{3+}$ readily forms various types of nitrate species in nitric acid according to the following equilibria:

$$
\begin{gathered}
\mathrm{Fe}(\mathrm{OH})^{2+}+\mathrm{H}_{2} \mathrm{O} \leftrightarrows \mathrm{Fe}(\mathrm{OH})_{2}^{+}+\mathrm{H}^{+} \\
\mathrm{Fe}^{3+}(\mathrm{aq})+\mathrm{HNO}_{3} \leftrightarrows \mathrm{Fe}\left(\mathrm{NO}_{3}\right)^{2+}+\mathrm{H}^{+} \\
\mathrm{Fe}\left(\mathrm{NO}_{3}\right)^{2+}+\mathrm{HNO}_{3} \leftrightarrows \mathrm{Fe}\left(\mathrm{NO}_{3}\right)_{2}^{+}+\mathrm{H}^{+} \\
\mathrm{Fe}\left(\mathrm{NO}_{3}\right)_{2}^{+}+\mathrm{HNO}_{3} \leftrightarrows \mathrm{Fe}\left(\mathrm{NO}_{3}\right)_{3}+\mathrm{H}^{+}
\end{gathered}
$$

In a reaction occurring in solution phase the reactive species partaking in a rate limiting step are considered mainly on the basis of results obtained from (i) acidity (pH), (ii) ionic strength $(\mu)$, and (iii) dielectric constant (solvent) variations on the rate of the reaction. But in the present investigation the reactions are conducted in nonaqueous $(\mathrm{MeCN})$ media containing PEG and Lewis bases (L) such as Phenanthroline $(\mathrm{L}=$ Phen). Literature reports show that Gaines Jr. et al. [18] earlier synthesized the solid crystalline complexes by direct mixing of the ligand to an aqueous solution of $\mathrm{Fe}$ (III) containing sulphate ions. From magnetic susceptibility data, it has been substantiated that the resultant complexes exhibited the composition of $[\mathrm{Fe}(\mathrm{III})] /[\mathrm{Phen}]=1 / 2$. They also mentioned that a greater stability of these $\left[\mathrm{Fe}(\mathrm{III}) \mathrm{L}_{2}\right]$ complexes is achieved when direct mixing is done in solution. If this contention has been more probable, the reciprocal plot of $1 / k^{\prime}$ versus $1 /[\text { Phen }]^{2}$ should have indicated a better linearity over $1 / k^{\prime}$ versus $1 /[$ Phen] plots. (Supplementary Tables S.12 to S.20 depict detailed kinetic data related to these plots. The plots are linear with very good to excellent correlation coefficients, see Tables S.12 to S.20 in Supplementary Material available online at http://dx.doi.org/10.1155/2013/703271). It is therefore reasonable to consider that $\mathrm{Fe}$ (III) nitrate binds with one unit of Phen to form 1:1 complex (i.e., [Fe(III)]/[Phen] $=1$ rather than 1/2). Further, the reactions are conducted under PEG environment in addition to Phen. It is also important 


$\begin{array}{cc}\text { Time }(\mathrm{min}) & 1 /\left(A_{\infty}-A_{t}\right) \\ 0 & 0.316448 \\ 60 & 0.685 \\ 120 & 1.029519 \\ 180 & 1.391746 \\ 240 & 1.788889 \\ 300 & 2.129492 \\ 360 & 2.460784 \\ 420 & 2.791176 \\ 480 & 3.2104\end{array}$

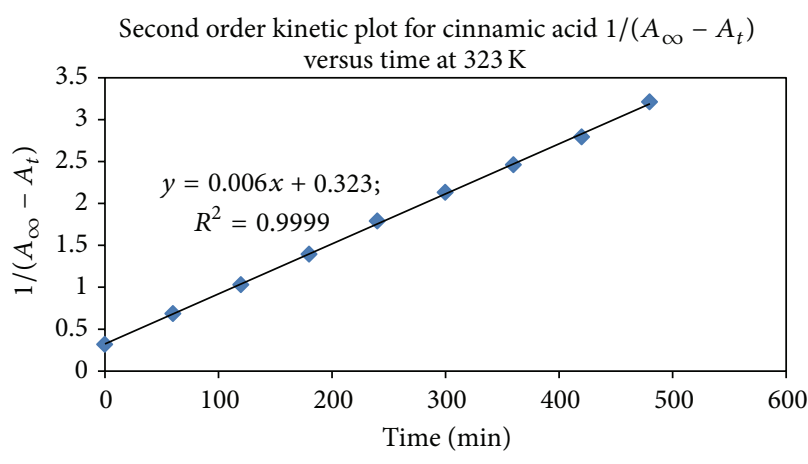

FIgURE 3: Second order kinetic plots of cinnamic acid $1 / A_{t}$ versus time at $323 \mathrm{~K}$. $[\mathrm{CA}]=6.25 \times 10^{-3} \mathrm{~mol} \mathrm{dm}^{-3} ;[\mathrm{Phen}]=6.25 \times 10^{-3} \mathrm{~mol} \mathrm{dm}{ }^{-3}$; $[\mathrm{Fe}(\mathrm{III})]=1.25 \times 10^{-3} \mathrm{~mol} \mathrm{dm}^{-3} ;\left[\right.$ PEG-200] $=9.37 \times 10^{-1} \mathrm{~mol} \mathrm{dm}^{-3}$.

$\begin{array}{cc}\text { Time }(\min ) & 1 /\left(A_{\infty}-A_{t}\right) \\ 0 & 0.237634 \\ 60 & 0.528235 \\ 120 & 0.749351 \\ 240 & 1.218143 \\ 360 & 1.781301 \\ 480 & 2.299863 \\ 600 & 2.782222 \\ 660 & 3.045455 \\ 720 & 3.33333\end{array}$

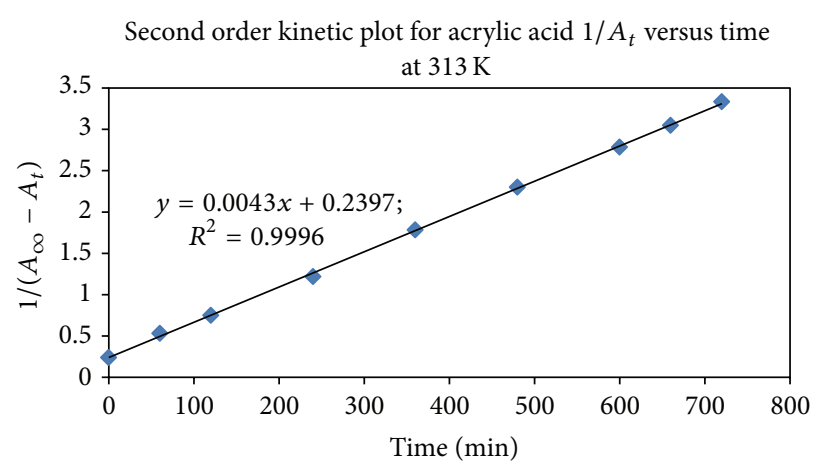

FIGURE 4: Second order kinetic plots of acrylic acid $1 / A_{t}$ versus time at $313 \mathrm{~K}$. $[\mathrm{AA}]=6.25 \times 10^{-3} \mathrm{~mol} \mathrm{dm}^{-3}$; $[\mathrm{Phen}]=6.25 \times 10^{-3} \mathrm{~mol} \mathrm{dm}{ }^{-3}$; $[\mathrm{Fe}(\mathrm{III})]=1.25 \times 10^{-3} \mathrm{~mol} \mathrm{dm}^{-3}[\mathrm{PEG}-200]=6.24 \times 10^{-1} \mathrm{~mol} \mathrm{dm}^{-3}$.

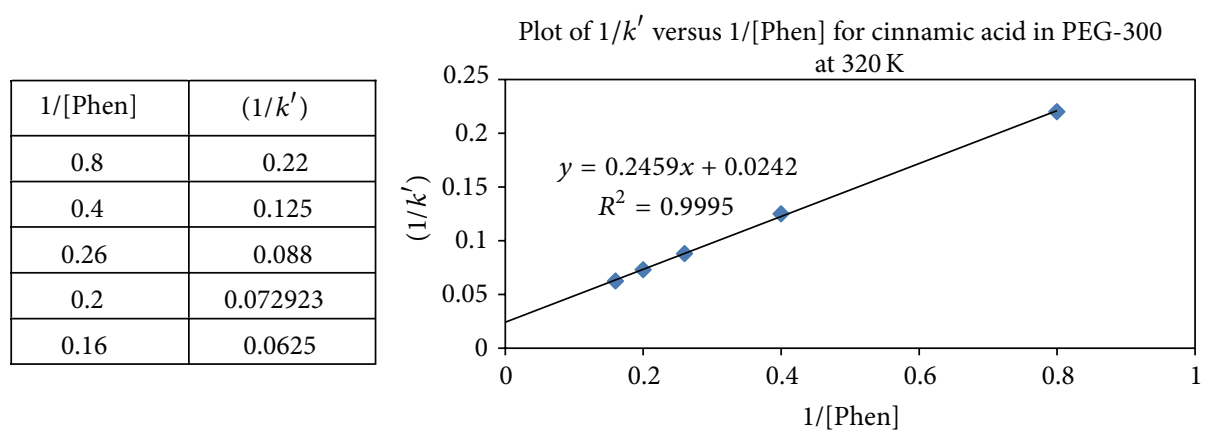

FIGURE 5: Effect of variation of [Phen] on first order $k^{\prime}$ of cinnamic acid in PEG-300, medium at $320 \mathrm{~K}$.

to consider that structural variation of PEG affected the rate of reaction considerably from PEG-200 to PEG-600 with a maximum activity with PEG-300. This observation probably supports the idea of PEG bound Fe(III) as reactive species in the present study.

3.3. Mechanism of Nitrodecarboxylation. The foregoing salient kinetics features, namely, first order in oxidant, first order dependence in, USA, and linearity of the plots of $1 / k^{\prime}$ versus $1 /[$ Phen] may probably indicate the formation of a precursor prior to the rate limiting decomposition step. According to
Gaines Jr. et al. [18], when polynuclear heterocyclic bases such as Phenanthroline are directly added to Fe(III) solutions, substitution liable yellow complexes of the type $\left[\mathrm{L}_{2} \mathrm{Fe}-\mathrm{O}\right.$ $\left.\mathrm{FeL}_{2}\right]^{4+}$ and $\left[\mathrm{Fe}(\mathrm{III}) \mathrm{L}_{2}\right]^{3+}$ resulted. However, in solution state $\left[\mathrm{Fe}(\mathrm{III}) \mathrm{L}_{2}\right]^{3+}$ is more likely to exist. Dimeric species of $\mathrm{Fe}(\mathrm{III})$ reactive species could be ruled out because of very low concentrations of Fe(III) $\left(\sim 10^{-4} \mathrm{~mol} \mathrm{dm}^{-3}\right)$ used in the present study. On the basis of foregoing discussions a most plausible mechanism for nitrodecarboxylation of unsaturated acids could be written as a sequence of reaction steps shown in Scheme 2. 


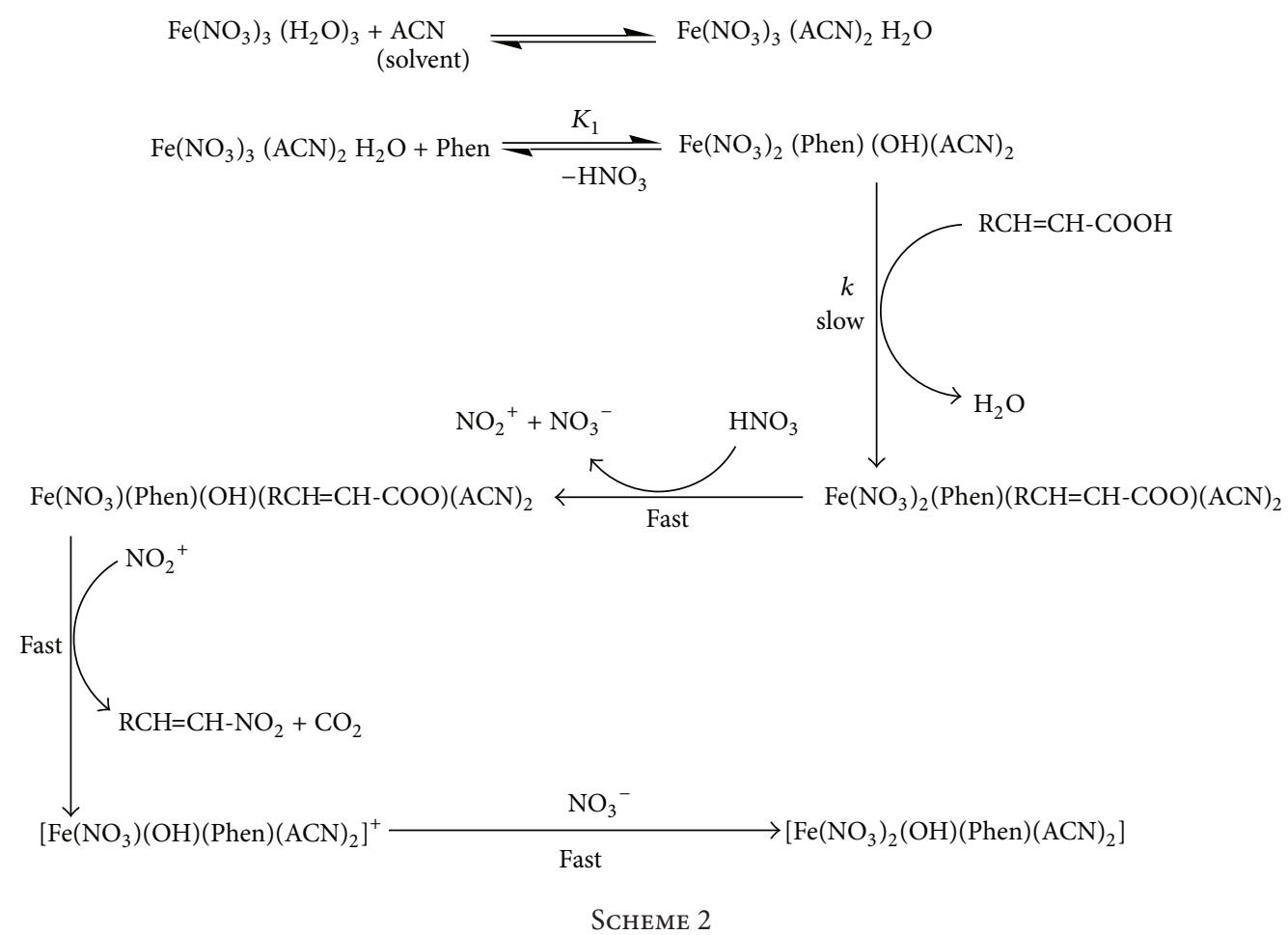

For the mechanism given in Scheme 2, the rate law was derived according to the following sequence of steps. From the second step of Scheme 2 we have

$$
\text { Rate }(\nu)=k\left[\mathrm{Fe}\left(\mathrm{NO}_{3}\right)_{2} \mathrm{~L}(\mathrm{OH})(\mathrm{ACN})_{2}\right][\mathrm{RCH}=\mathrm{CH}-\mathrm{COOH}]
$$

Considering the total concentration of $\left([\mathrm{M}]_{\text {tot }}\right)$ as the algebraic sum of free metal ion species and metal ion boundligand (complex) species,

$$
[\mathrm{M}]_{\mathrm{tot}}=[\mathrm{M}]+[\mathrm{ML}]
$$

From metal ion-ligand binding equilibrium,

$$
K_{1}=\frac{[\mathrm{ML}]}{[\mathrm{M}][\mathrm{L}]} \quad \text { or } \quad[\mathrm{M}]=\frac{[\mathrm{ML}]}{K_{1}[\mathrm{~L}]}
$$

Substitution of $[\mathrm{M}]$ in (7) gives

$$
\begin{aligned}
& \frac{[\mathrm{ML}]}{\left(K_{1}[\mathrm{~L}]\right)}+[\mathrm{ML}]=[\mathrm{M}]_{\text {tot }} \\
& {[\mathrm{ML}]\left(1+K_{1}[\mathrm{~L}]\right)=[\mathrm{M}]_{\text {tot }} K_{1}[\mathrm{~L}] } \\
& {[\mathrm{L}] \approx C_{\mathrm{L}} } \\
& {[\mathrm{ML}]=\frac{[\mathrm{M}]_{\text {tot }} K_{1} C_{\mathrm{L}}}{\left(1+K_{1} C_{\mathrm{L}}\right)} }=\frac{K_{1}[\mathrm{Fe}(\mathrm{III})][\mathrm{Phen}]}{\left(1+K_{1}[\text { Phen }]\right)} \\
& \text { Or }\left[\mathrm{Fe}^{+}\left(\mathrm{NO}_{3}\right)_{2} \mathrm{~L}\right]=[\mathrm{ML}] \\
&=\frac{K_{1}[\mathrm{M}] C_{\mathrm{L}}}{1+K_{1}[\mathrm{~L}]} \\
&=\frac{K_{1}[\mathrm{Fe}(\mathrm{III})][\text { Phen }]}{1+K_{1}[\text { Phen }]}
\end{aligned}
$$

Substituting this in rate limiting step (6), rate law comes out as

$$
\nu=\frac{k K_{1}[\mathrm{Fe}(\mathrm{III})][\mathrm{Phen}][\mathrm{USA}]}{\left(1+K_{1}[\mathrm{Phen}]\right)}
$$

This equation is in accordance with all the observed kinetic features. According to the reciprocal form of (10), plots of $1 / k^{\prime}$ versus $1 /[$ Phen] have been realized in the present study showing the validity of the proposed mechanism. From the observed straight line plots with positive slope $(m)$ and intercept $(C)$ kinetic constants $K_{1}$ and $k$ could be evaluated, where

$$
\begin{array}{ll}
m=\frac{1}{k K_{1}}, & C=\frac{1}{k}, \\
K_{1}=\frac{C}{m}, & k=\frac{1}{C} .
\end{array}
$$

Formation constants $\left(K_{1}\right)$ and rate constant $(k)$ data are presented in Tables 3 and 4 (for details, please refer to Tables S.1 to S.20 in Supplementary Material).

3.4. Effect of [PEG] on Mechanism of Nitrodecarboxylation. Progress of the reaction has been studied in the presence of different PEGs with varied structures. Reaction rates are significantly influenced by the structural variation and concentration of PEG, which can be attributed to the electron density on polyoxyethylene moiety of PEG with an increase in methyl groups, and found that the reaction is accelerated by all the PEGs with an increasing order: PEG-200 < PEG-300 > PEG-400 > PEG-600 > PEG-6000. This could be attributed to the negative charge developed on polyoxyethylene moiety of 


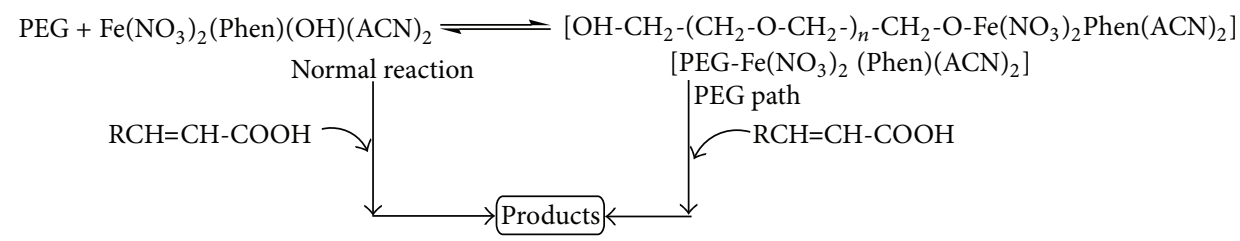

SCHEME 3

TABLE 3: Activation parameters involving rate constant $(k)$.

\begin{tabular}{lccccc}
\hline Substrate & PEG & $\begin{array}{c}k \\
\mathrm{dm}^{3} \mathrm{~mol}^{-1} \mathrm{~s}^{-1} \\
310 \mathrm{~K}\end{array}$ & $\begin{array}{c}\Delta H^{\#} \\
\mathrm{~kJ} / \mathrm{mol}\end{array}$ & $\begin{array}{c}\Delta G^{\#} \\
\mathrm{~J} / \mathrm{K} / \mathrm{mol}\end{array}$ \\
\hline \multirow{2}{*}{ Cinnamic } & 300 & 2318 & 21.7 & 56.2 & -111 \\
acid & 400 & 5925 & 58.8 & 62.0 & -10.2 \\
& 600 & 2857 & 23.8 & 56.2 & -104 \\
& 200 & 3404 & 36.5 & 55.7 & -62.0 \\
\hline \multirow{3}{*}{ Crotonic } & 300 & 5925 & 37.2 & 54.6 & -78.6 \\
acid & 400 & 2000 & 38.4 & 56.0 & -54.0 \\
& 600 & 2857 & 43.9 & 54.5 & -34.2 \\
\hline \multirow{3}{*}{ Acrylic } & 300 & 1975 & 23.8 & 56.2 & -104 \\
acid & 400 & 3636 & 46.9 & 54.0 & -23.1 \\
& 600 & 3404 & 44.0 & 54.2 & -33.2 \\
& 200 & 1584 & 18.3 & 56.6 & -122 \\
Methoxy & 300 & 5333 & 34.5 & 66.6 & 4.0 \\
cinnamic & 400 & 3018 & 75.2 & 72.9 & 7.5 \\
acid & 600 & 2857 & 36.5 & 38.8 & -7.4 \\
\hline Nitro & 200 & 2318 & 21.0 & 56.2 & -113 \\
cinnamic & 300 & 5925 & 54.8 & 55.1 & -1.1 \\
acid & 400 & 3404 & 41.3 & 54.3 & -41.7 \\
& 600 & 3809 & 38.2 & 54.4 & -52.5 \\
\hline
\end{tabular}

PEG in the lines of nonionic micelles such as TX and oxidant species as mentioned above. Mechanism could probably fit into the Menger and Portnoy $[29,30]$ model which closely resembles that of an enzymatic catalysis. According to this model, formation of micelle-substrate complex (MS) could occur in the preequilibrium step due to the interaction of substrate $(\mathrm{S})$ with micelle $(\mathrm{M})$. The complex thus formed may possess higher or lower reactivity to gives products. The catalytic activity of PEG could be explained through the formation of (PEG bound Fe(III)L) by binding model.

$$
\begin{gathered}
\text { PEG }+\left[\mathrm{Fe}\left(\mathrm{NO}_{3}\right)_{2} \text { Phen }(\mathrm{OH})(\mathrm{ACN})_{2}\right] \\
\rightleftharpoons\left[\mathrm{OH}-\mathrm{CH}_{2}-\left(\mathrm{CH}_{2}-\mathrm{O}-\mathrm{CH}_{2}-\right)_{n}\right. \\
\left.\quad-\mathrm{CH}_{2}-\mathrm{O}-\mathrm{Fe}\left(\mathrm{NO}_{3}\right)_{2} \text { Phen }(\mathrm{ACN})_{2}\right] \\
+\mathrm{H}_{2} \mathrm{O} \\
{\left[\text { PEG-Fe }\left(\mathrm{NO}_{3}\right)_{2} \text { Phen }(\mathrm{OH})(\mathrm{ACN})_{2}\right]}
\end{gathered}
$$

\begin{tabular}{|c|c|c|c|c|c|}
\hline \multirow[t]{2}{*}{ Substrate } & \multirow{2}{*}{$\begin{array}{l}\text { PEG } \\
200\end{array}$} & $\begin{array}{c}K_{1} \\
\mathrm{dm}^{3} \mathrm{~mol}^{-1} \text { at } \\
310 \mathrm{~K}\end{array}$ & \multicolumn{2}{|c|}{$\mathrm{kJ} / \mathrm{mol}$} & \multirow{2}{*}{$\begin{array}{c}\Delta S \\
\mathrm{~J} / \mathrm{K} / \mathrm{mol} \\
38.2\end{array}$} \\
\hline & & 0.307 & 14.9 & 3.0 & \\
\hline \multirow{4}{*}{$\begin{array}{l}\text { Cinnamic } \\
\text { acid }\end{array}$} & 300 & 0.067 & 44.8 & 4.4 & 130 \\
\hline & 400 & 0.618 & 22.8 & 1.2 & 69.6 \\
\hline & 600 & 0.350 & 6.6 & 2.7 & 12.6 \\
\hline & 200 & 0.176 & 137 & 3.61 & 430 \\
\hline \multirow{4}{*}{$\begin{array}{l}\text { Crotonic } \\
\text { acid }\end{array}$} & 300 & 0.078 & 126 & 6.85 & 384 \\
\hline & 400 & 0.356 & 118 & 10.21 & 347 \\
\hline & 600 & 0.224 & 128 & 5.35 & 395 \\
\hline & 200 & 0.618 & 25.0 & 1.2 & 76.7 \\
\hline \multirow{3}{*}{$\begin{array}{l}\text { Acrylic } \\
\text { acid }\end{array}$} & 300 & 0.172 & 50.7 & 4.5 & 149 \\
\hline & 400 & 0.085 & 20.2 & 6.3 & 44.0 \\
\hline & 600 & 0.362 & 9.6 & 2.00 & 22.4 \\
\hline \multirow{4}{*}{$\begin{array}{l}\text { Methoxy } \\
\text { cinnamic } \\
\text { acid }\end{array}$} & 200 & 0.284 & 21.7 & 3.2 & 59.7 \\
\hline & 300 & 0.123 & 44.8 & 4.3 & 130 \\
\hline & 400 & 0.281 & 30.1 & 3.3 & 86.7 \\
\hline & 600 & 0.350 & 6.6 & 2.7 & 12.6 \\
\hline \multirow{4}{*}{$\begin{array}{l}\text { Nitro } \\
\text { cinnamic } \\
\text { acid }\end{array}$} & 200 & 0.350 & 14.9 & 3.04 & 38.3 \\
\hline & 300 & 0.470 & 23.5 & 2.0 & 69.6 \\
\hline & 400 & 0.109 & 52.0 & 5.7 & 149 \\
\hline & 600 & 0.119 & 69.6 & 5.5 & 206 \\
\hline
\end{tabular}

TABLE 4: Thermodynamic parameters involving formation constant $\left(K_{1}\right)$.

A general mechanism is proposed by considering the bulk phase and micellar phase reactions as shown in Scheme 3.

Data presented in Table 1 show that the reactions are too sluggish with longer reaction times ( $>24 \mathrm{hrs}$ ) even under reflux conditions, while remarkable rate enhancements associated with shorter reaction times and enhanced product yields are observed in PEG mediated reactions. On the basis of these observations, mechanism of PEG mediated reactions could be explained with the participation of unsaturated acid and PEG-bound-Fe(III) nitrate species in the slow step as shown in Scheme 4.

3.5. Effect of Structure on Enthalpy and Entropy Changes. When a series of structurally related substrates undergo the same general reaction or when the reaction conditions for a single substrate are changed in a systematic way, 

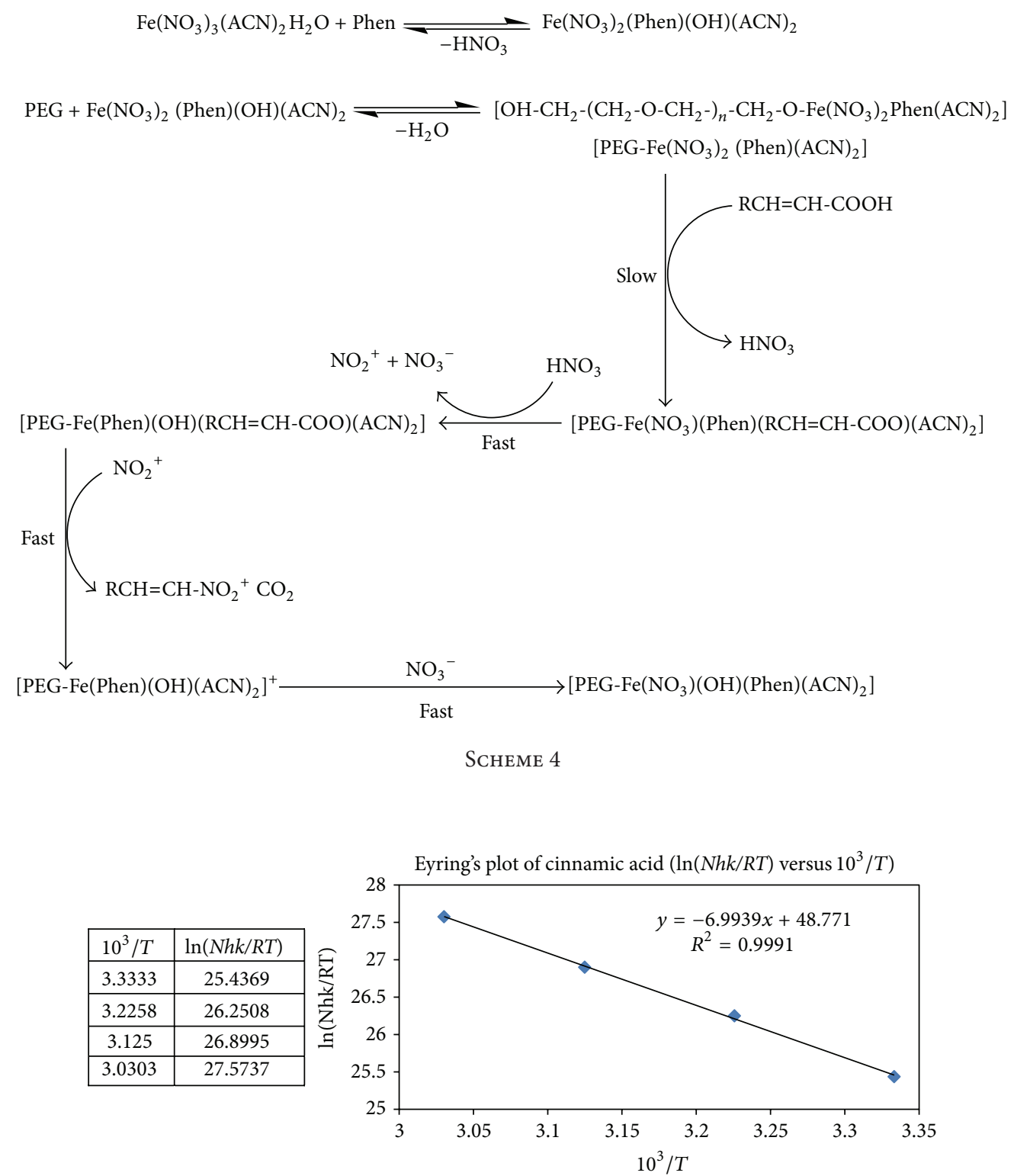

FIGURE 6: Eyring's plot of cinnamic acid $\left(\ln (N h k / R T)\right.$ versus $\left.10^{3} / T\right)$. Kinetic study with [PEG-300] $=6.24 \times 10^{-1} \mathrm{~mol} \mathrm{dm}^{-3}$.

a considerable variation in the enthalpies and entropies of activation is more likely. The entropy of activation $\left(\Delta S^{\#}\right)$ provides important information about the transition state and molecularity of the rate-determining step in the reaction path. Positive values for $\Delta S^{\#}$ suggest that entropy increases upon achieving the transition state, which often indicates a dissociative mechanism. Negative values for $\Delta S^{\#}$ indicate that entropy decreases upon achieving the transition state, which often indicates an associative mechanism.

Eyring plots for rate constant $(k)$ variation with temperature (Figures 6 and 7) are linear, and related activation parameters data are presented in Table 3 (more details of these plots are given in Supplementary Tables S.21 to S.25). A positive change in entropy of activation compiled in Table 3 probably indicates a more disordered transition state. Degrees of freedom are "liberated" ongoing from the ground state to the transition state and the reaction is fast. These results probably support the release of proton from PEG and nitrate from $\mathrm{Fe}(\mathrm{III})$ moieties, which readily brings about changes in the transition state and causes simultaneous association and dissociation of species, causing a greater disorderliness in the transition state leading to a chemical reaction. Similar trends are recorded in all the PEGs used in this study. The free energy of activation for all the systems is negative (i.e., $\Delta G^{\#}<0$ ) indicating that the reaction is spontaneous.

Further, Vant Hoff's plots (Figures 8 and 9) of $\ln K_{1}$ versus $(1 / T)$ are also linear with negative slopes indicating the endothermic nature of the equilibrium. Related activation parameters are evaluated from these plots and the data are presented in Table 4 (more details of these plots are given in Supplementary Tables S.26 to S.30). Entropy 


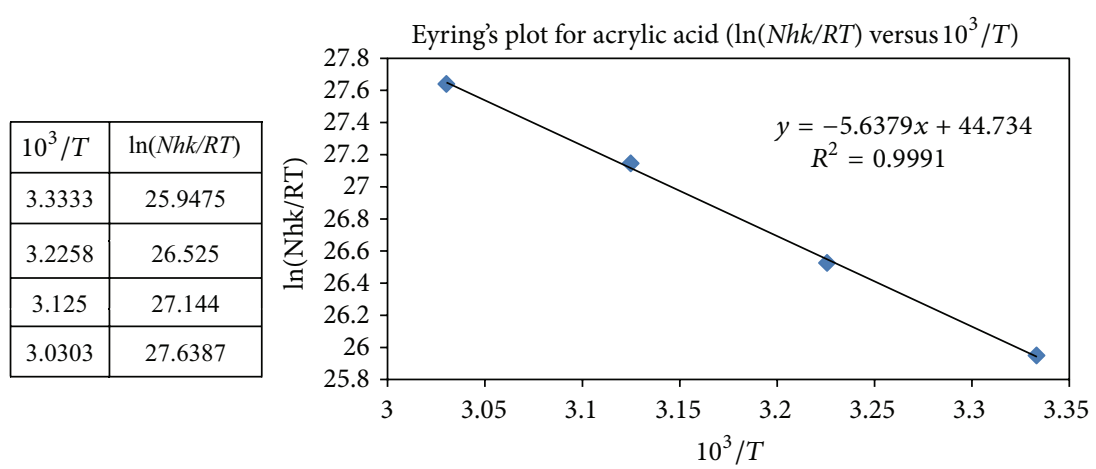

Figure 7: Eyring's plot of acrylic acid $\left(\ln (\mathrm{Nhk} / R T)\right.$ versus $\left.10^{3} / T\right)$. Kinetic study with $[\mathrm{Phen}]=3.75 \times 10^{-3} \mathrm{~mol} \mathrm{dm}^{-3}$; [PEG-300] $=6.24 \times$ $10^{-1} \mathrm{~mol} \mathrm{dm}^{-3} ;[\mathrm{Fe}(\mathrm{III})]=1.25 \times 10^{-3} \mathrm{~mol} \mathrm{dm}^{-3}$.

\begin{tabular}{|c|c|}
\hline $10^{3} / T$ & $4+\ln (K)$ \\
\hline 3.3333 & 2.9387 \\
\hline 3.2258 & 3.2104 \\
\hline 3.125 & 3.5188 \\
\hline 3.0303 & 3.7608 \\
\hline
\end{tabular}

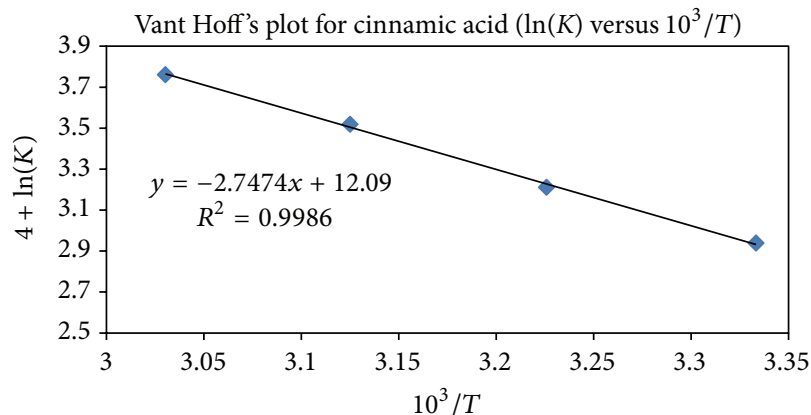

FIGURE 8: Vant Hoff's plot of cinnamic acid $\left(\ln (K)\right.$ versus $\left.10^{3} / T\right)$. Kinetic study with $\left[\right.$ PEG-300] $=6.24 \times 10^{-1} \mathrm{~mol} \mathrm{dm}^{-3}$.

\begin{tabular}{|c|c|}
\hline $10^{3} / T$ & $4+\ln (K)$ \\
\hline 3.3333 & 1.369 \\
\hline 3.2258 & 2.04 \\
\hline 3.125 & 2.665 \\
\hline 3.0303 & 3.214 \\
\hline
\end{tabular}

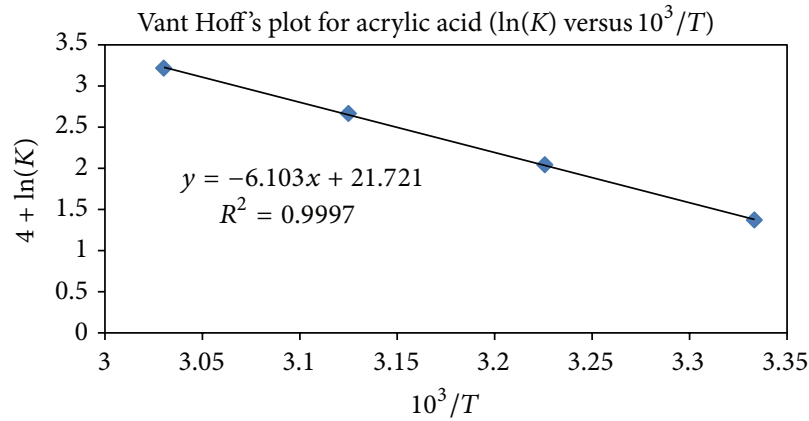

Figure 9: Vant Hoff's plot of acrylic acid $\left(\ln (K)\right.$ versus $\left.10^{3} / T\right)$. Kinetic study with $[$ Phen $]=3.75 \times 10^{-3} \mathrm{~mol} \mathrm{dm}^{-3}[\mathrm{PEG}-300]=6.24 \times$ $10^{-1} \mathrm{~mol} \mathrm{dm}^{-3} ;[\mathrm{Fe}(\mathrm{III})]=1.25 \times 10^{-3} \mathrm{~mol} \mathrm{dm}^{-3}$.

values compiled in Table 4 of the present study are highly positive, which indicate greater instability and are prone to decompose or move towards another reactant to give products by interacting with it. Very small $\Delta G$ values support this contention, which also show the nonspontaneous and unstable equilibrium.

\section{Conclusions}

The observed catalytic activity of PEGs could be explained in the lines of nonionic micelles (TX). The slight negative charge developed on polyoxyethylene groups probably interact with cationic form(s) of Fe(III) chelates in the intermediate stages and enhances the rate of reaction.

\section{References}

[1] P. T. Anastasas and J. C. Warner, Green Chemistry: Theory and Practice, Oxford University Press, New York, NY, USA, 1988.

[2] R. A. Sheldon, "Catalysis and pollution prevention," Chemistry and Industry, vol. 1, pp. 12-15, 1997.

[3] J. H. Clark, "Green chemistry: challenges and opportunities," Green Chemistry, vol. 1, no. 1, pp. 1-8, 1999.

[4] R. Kumar, P. Chaudhary, S. Nimesh, and R. Chandra, "Polyethylene glycol as a non-ionic liquid solvent for Michael addition reaction of amines to conjugated alkenes," Green Chemistry, vol. 8, no. 4, pp. 356-358, 2006.

[5] J. M. Harris, Poly(Ethylene Glycol) Chemistry, Biotechnological and Biomedical Applications, Plenum Press, New York, NY, USA, 1992. 
[6] J. M. Harris, Polyethylene Glycol: Chemistry and Biological Application, ACS Books, Washington, DC, USA, 1997.

[7] J. Hamelin, J. P. Bazureau, F. Texier-Boullet, and A. Louby, Microwave in Organic Synthesis, Wiley-VCH, Weinheim, Germany, 2002.

[8] G. R. Desiraju and B. S. Goud, in Reactivity of Solids: Present, Past and Future, V. V. Boldyrev, Ed., p. 223, Blackwell Sciencs, London, UK, 1995.

[9] M. M. Ali, T. Tasneem, K. C. Rajanna, and P. K. Sai Prakash, "An efficient and facile synthesis of 2-chloro-3-formyl quinolines from acetanilides in micellar media by Vilsmeier-Haack cyclisation," Synlett, no. 2, pp. 251-253, 2001.

[10] M. M. Ali, S. Sana, Tasneem, K. C. Rajanna, and P. K. Saiprakash, "Ultrasonically accelerated Vilsmeier-Haack cyclisation and formylation reactions," Synthetic Communications, vol. 32, no. 9, pp. 1351-1356, 2002.

[11] K. C. Rajanna, M. M. Ali, S. Sana, Tasneem, and P. K. Saiprakash, "Vilsmeier-Haack acetylation in micellar media: an efficient one pot synthesis of 2-chloro-3-acetyl quinolines," Journal of Dispersion Science and Technology, vol. 25, no. 1, pp. 17-21, 2004.

[12] S. Sana, K. C. Rajanna, M. M. Ali, and P. K. Saiprakash, "Mild, efficient and selective nitration of anilides, non-activated and moderately activated aromatic compounds with ammonium molybdate and nitric acid as a new nitrating agent," Chemistry Letters, no. 1, pp. 48-49, 2000.

[13] S. Sana, M. M. Ali, K. C. Rajanna, and P. K. Saiprakash, in Proceedings of the Second National Symposium in Chemistry, Indian Institute of Chemical Technology, Hyderabad, India, January 2000.

[14] Tasneem, M. M. Ali, K. C. Rajanna, S. Sana, and P. K. Saiprakash, "Ammonium nickel sulfate mediated nitration of aromatic compounds with nitric acid," Synthetic Communications, vol. 31, no. 7, pp. 1123-1127, 2001.

[15] F. Blau, "Über neue organische Metallverbindungen," Monatshefte für Chemie und verwandte Teile anderer Wissenschaften, vol. 19, no. 1, pp. 647-689, 1898.

[16] G. S. Laurence and K. J. Ellis, "The detection of a complex intermediate in the oxidation of ascorbic acid by ferric ion," Journal of the Chemical Society, Dalton Transactions, no. 15, pp. 1667-1670, 1972.

[17] R. A. Whiteker and N. Davidson, "Ion-exchange and spectrophotometric investigation of iron(III) sulfate complex ions," Journal of the American Chemical Society, vol. 75, no. 13, pp. 3081-3085, 1953.

[18] A. Gaines Jr., L. P. Hammett, and G. H. Walden Jr., "The structure and properties of mononuclear and polynuclear phenanthroline-ferric complexes," Journal of the American Chemical Society, vol. 58, no. 9, pp. 1668-1674, 1936.

[19] C. Hunsdiecker and H. Hunsdiecker, "Degradationof the salts of aliphatic acids by bromine," Berichte der Deutschen Chemischen Gesellschaft, vol. 75, pp. 291-297.

[20] C. Hunsdiecker and H. Hunsdiecker, "Degradation of the salts of aliphatic acids by bromine," Chemical Abstracts, vol. 37, article 23114, 1943.

[21] C. Hunsdiecker, H. Hunsdiecker, and E. Vogt, Chemical Abstracts, vol. 31, p. 2233, 1937.

[22] S. Chowdhury and S. Roy, "Manganese (II) catalysed Hunsdiecker reaction: a facile entry to $\alpha$-(dibromomethyl) benzenemethanol," Tetrahedron Letters, vol. 37, no. 15, pp. 2623-2624, 1996.
[23] S. Chowdhury and S. Roy, "The first example of a catalytic Hunsdiecker reaction: synthesis of $\beta$-halostyrenes," Journal of Organic Chemistry, vol. 62, no. 1, pp. 199-200, 1997.

[24] D. Naskar, S. Chowdhury, and S. Roy, "Is metal necessary in the Hunsdiecker-Borodin reaction?" Tetrahedron Letters, vol. 39, no. 7, pp. 699-702, 1998.

[25] D. Naskar and S. Roy, "1-Haloalkynes from propiolic acids: a novel catalytic halodecarboxylation protocol," Journal of Organic Chemistry, vol. 64, no. 18, pp. 6896-6897, 1999.

[26] D. Naskar and S. Roy, "Catalytic hunsdiecker reaction and one-pot catalytic Hunsdiecker-Heck strategy: synthesis of $\alpha, \beta$-unsaturated aromatic halides, $\alpha$-(dihalomethyl)benzenemethanols, 5-aryl-2,4-pentadienoic acids, dienoates and dienamides," Tetrahedron, vol. 56, no. 10, pp. 1369-1377, 2000.

[27] D. Naskar, S. K. Das, L. Giribabu, B. G. Maiya, and S. Roy, "Novel catalytic Hunsdiecker-Heck $(\mathrm{CHH})$ strategy toward all-E stereocontrolled ferrocene-capped conjugated push-pull polyenes," Organometallics, vol. 19, no. 8, pp. 1464-1469, 2000.

[28] J. Prakash Das and S. Roy, "Catalytic Hunsdiecker reaction of $\alpha, \beta$-unsaturated carboxylic acids: how efficient is the catalyst?" Journal of Organic Chemistry, vol. 67, no. 22, pp. 7861-7864, 2002.

[29] R. G. Johnson and R. K. Ingham, "The degradation of carboxylic acid salts by means of halogen-the hunsdiecker reaction," Chemical Reviews, vol. 56, no. 2, pp. 219-269, 1956.

[30] A. G. Smith, Organic Synthesis, Wiley Interscience, New York, NY, USA, 1993. 

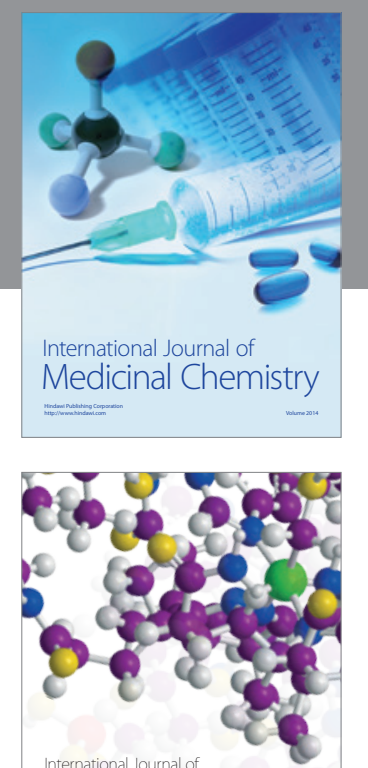

\section{Carbohydrate} Chemistry

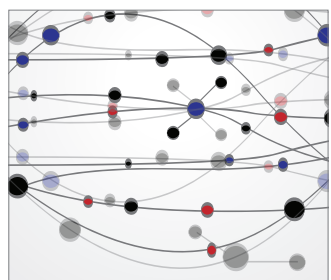

The Scientific World Journal
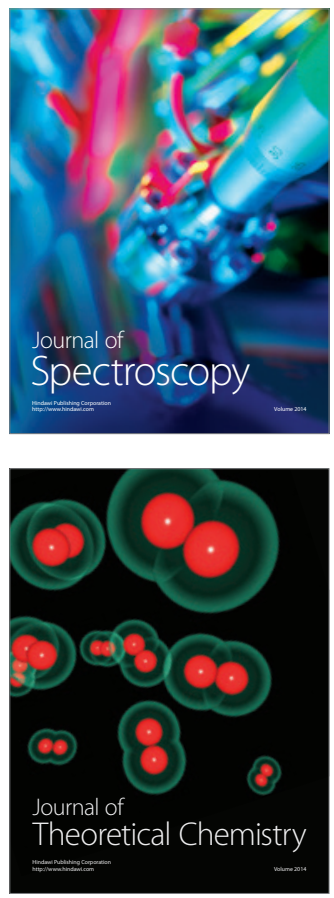
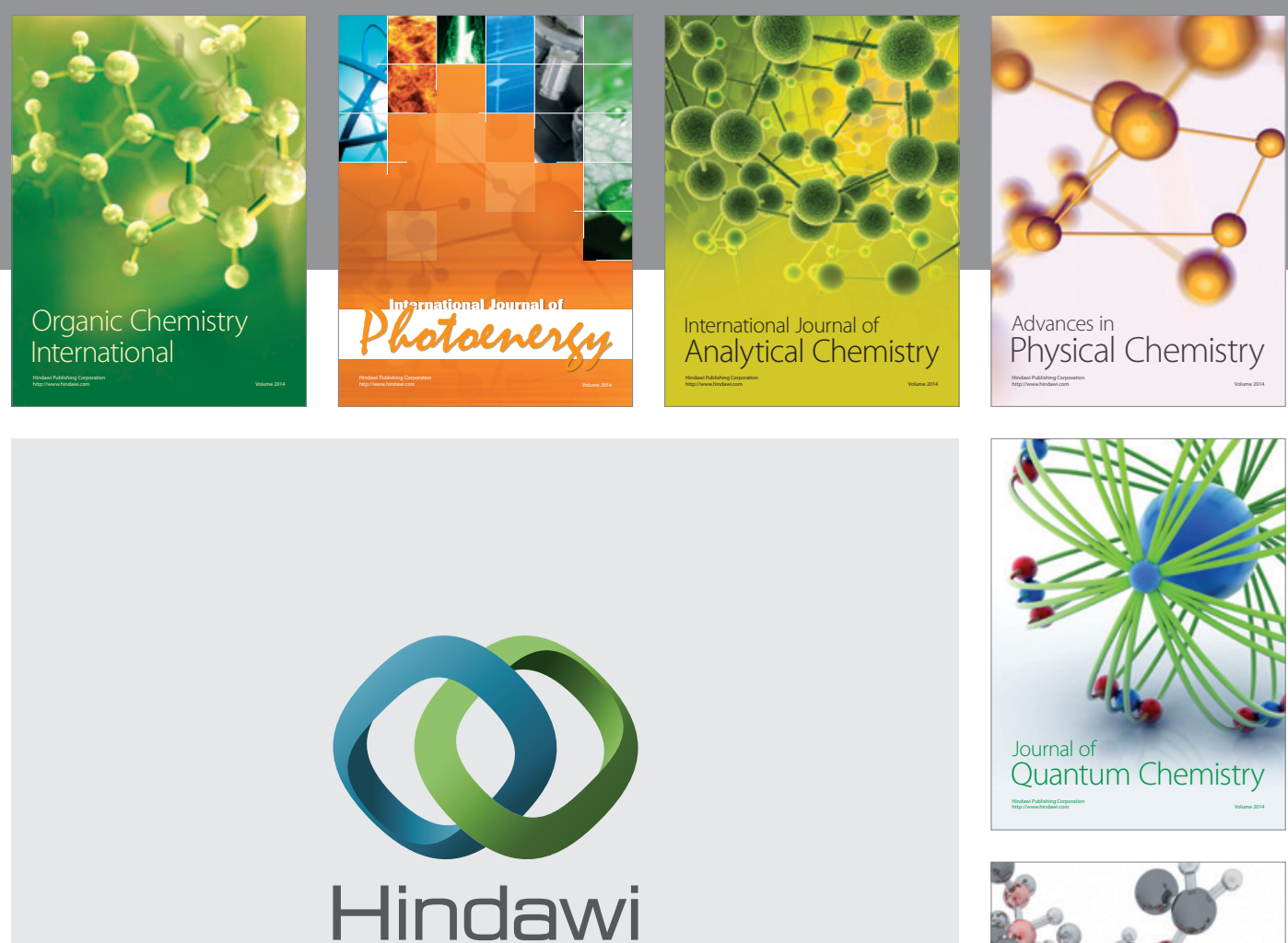

Submit your manuscripts at

http://www.hindawi.com

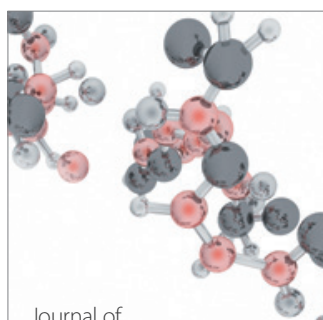

Analytical Methods

in Chemistry

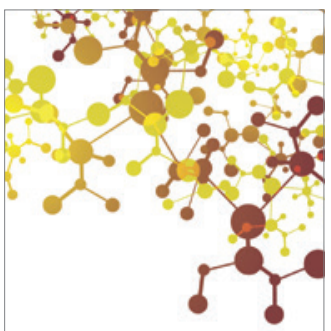

Journal of

Applied Chemistry

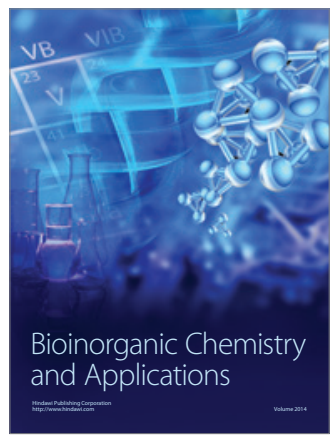

Inorganic Chemistry
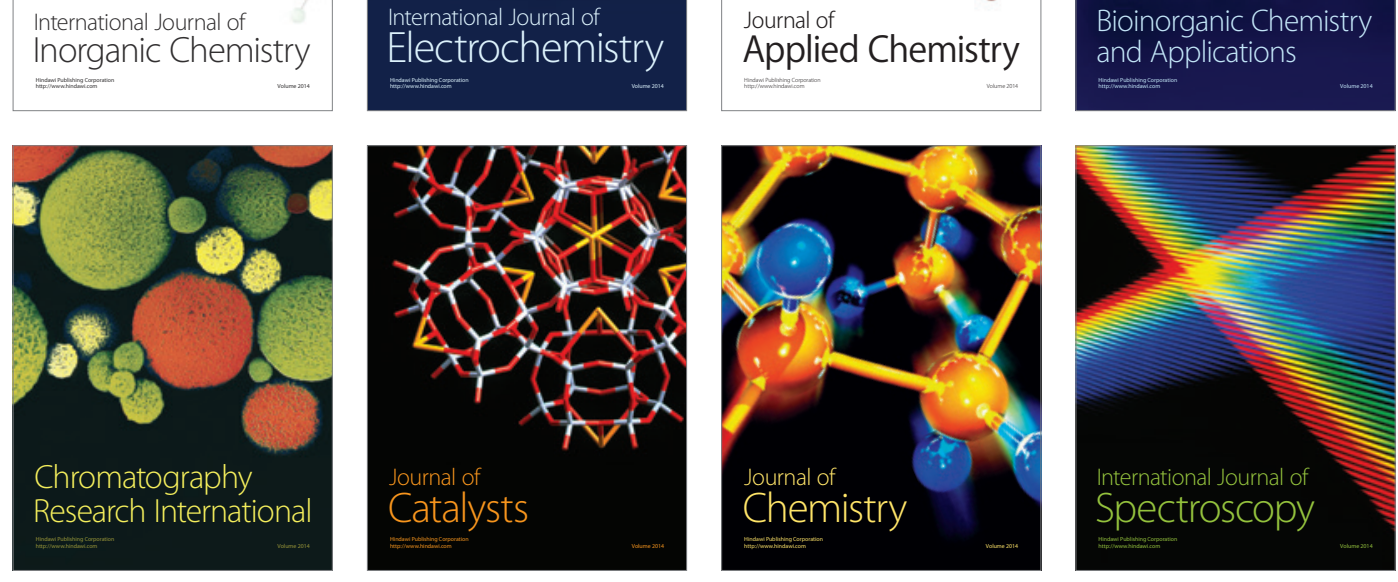